\title{
A terceira geração de ouvintes e a formulação do gosto musical
}

\section{Third generation listeners and music taste formulation}

\begin{abstract}
Mônica Panis Kaseker I mkaseker@gmail.com Jornalista graduada pela PUC-PR, é doutora em Sociologia (UFPR), professora do Curso de Comunicação Social da PUC-PR e professora colaboradora do Programa de Pós-Graduação em Sociologia da UFPR.
\end{abstract}

\begin{abstract}
Resumo
Com a internet, foram desenvolvidos novos fluxos de circulação musical, mais independentes das gravadoras e emissoras de rádio. Porém, uma investigação junto a jovens ouvintes, inicialmente focada na escuta radiofônica, se depara com um contexto de múltiplas mediaçôes, em que a internet se desenvolve cada vez mais como agente da indústria cultural, ao participar da formulação do gosto musical.
\end{abstract}

Palavras-Chave: Ouvintes; Rádio; Música

\begin{abstract}
After the Internet, new flows have been developed for musical circulation, more independent from the record companies and the radio stations. This research, that involves young radio listeners, reveals a context of multiple mediations in which the Internet develops as another agent of cultural industry, participating in the formulation of musical preferences.
\end{abstract}

Keywords: Listeners; Radio; Music 


\section{Para além do rádio}

$\mathrm{O}$ rádio foi um dos fenômenos que inauguraram o período da comunicação de massa, no início do século XX. Juntamente com as gravadoras, o veículo ditava os sucessos que seriam distribuídos e reproduzidos a milhóes de ouvintes em todo o mundo. $\mathrm{O}$ crescimento industrial do rádio deu um aspecto abstrato ao ouvinte como categoria social. De acordo com Matallana, é importante notar que a massividade, no entanto, estabeleceu um diálogo permanente com a cultura popular.

\section{[...] hecho que puede comprobarse en la constante interrelación entre los gustos del público y la programación: los cambios en las audiencias fueron acompañados por la modernización empresarial, y la radio y el público se volvieron masivos simultáneamente. La radio actuó como mecanismo de integración social y llegó a todos los rincones del pais con una programación heterogénea que mostro valores y costumbres "universales" combinados con elementos cotidianos y locales. (MATALLANA, 2006, p. 18)}

Por muito tempo o rádio foi um dos principais elementos na formação do gosto musical do público. A lógica da audiência e da publicidade, no entanto, imperaram por décadas na escolha do que seria ouvido. Para Adorno, a modernidade causou uma regressão na audição. $\mathrm{Na}$ sociedade capitalista, a música "ligeira" é mero entretenimento e desobriga o ouvinte a pensar, servindo apenas como pano de fundo. "Se ninguém mais é capaz de falar realmente, é óbvio também que já ninguém é capaz de ouvir” (ADORNO, 1980, p. 80). Mesmo a música clássica ganhou um novo "valor", o de consumo, ou seja, o que importa é que seja consumida, mesmo que não compreendida. Vale aqui ressaltar que a indústria cultural oferece um elenco de produtos a serem consumidos e simula a diversidade num repertório preestabelecido de escolhas.

Desde a implantação do rádio no Brasil em 1922, passando pela sua Era de Ouro nos anos 1940 e 1950, quando ocorreu o ápice de sua importância na indústria cultural brasileira, muitas transformaçôes sociais, tecnológicas e mercadológicas ocorreram nesse contexto. $\mathrm{Na}$ atualidade, algumas mudanças tecnológicas no rádio devem ser apontadas: a escuta crescente pelo celular, pela internet, pela TV a cabo e no carro. Além disso, a possibilidade de que o som do rádio passe a ser acompanhado por pequenos textos e imagens no rádio digital, o que já acontece nos sites das emissoras de rádio na Internet, ou seja, a convergência. Essas transformaçóes vão tomando forma lentamente, na medida em que as diferentes geraçóes se apropriam dessas tecnologias.

Com os suportes digitais, há uma reconfiguração da circulação de mensagens em áudio. $\mathrm{O}$ rádio na internet não se restringe à disponibilização da programação das emissoras tradicionais online, há também as rádios veiculadas exclusivamente na rede, as radiowebs, que podem ter programação ao vivo ou disponibilizar arquivos on demand, que configuram o podcast, ou seja, o usuário escolhe o que deseja ouvir e o faz no momento em que julgar mais apropriado. Se o arquivo náo o interessar ou tornar-se cansativo, ele pode interromper a escuta quando bem entender. Além dos conteúdos que 
têm como referência o rádio, arquivos sonoros dos mais variados tipos podem ser encontrados em sites, blogs e portais. A própria memória do rádio é o tema de muitas postagens individuais no acervo da rede. A produçáo e circulação musical também ganharam novas dimensôes e perspectivas, escapando do controle da indústria fonográfica.

Depois de superar uma fase inicial de redifundir a programação das emissoras hertzianas na internet, as rádios passaram a integrar sua produção à lógica da rede. Para Cebrián Herreros, surge aí a ciberrádio, que atribui outro papel à audiência, mais interativo. Numa terceira etapa, são criadas as primeiras emissoras pensadas para a internet, quando os internautas passam a produzir sua própria programação. Mais recentemente, as inovaçôes da rede estão sendo objeto de experimentaçóes de outras modalidades e extensóes da ciberrádio (CEBRIÁN HERREROS, 2008, p. 36).

Ainda se explora pouco as possibilidades do áudio na rede, como os hiperlinks, na construção de links relacionando os diversos áudios ou a disponibilização de produtos e/ou programas de forma a permitir a navegação dos internautas pelos seus blocos e segmentos.

Para Cebrián Herreros (2008, p. 45), a interatividade no rádio deve ser entendida como um constante diálogo entre todos os integrantes do processo comunicativo: usuários-designers-programadores e usuários-buscadores-consumistas. "El proceso comunicativo es el resultado de los desarrollos de tales diálogos y usos."

Além da interatividade, que prevê a manipulação e a influência do usuário sobre sua própria experiência com os meios, a tecnologia digital pressupóe um modelo comunicativo que conjugue integração, hipermidialidade e imersão. Isso tem muito a dizer sobre o que pode ser o futuro do áudio na internet. A integração se refere à combinação entre diferentes formas de expressão, como sons, imagens e textos. A hipermidialidade é a oferta de interconexôes a serem acionadas de acordo com a vontade do usuário. E a imersão está relacionada ao envolvimento do internauta em uma navegação entre formas e apresentaçóes não lineares e desencadeadas.

Para Yúdice, as novas tecnologias fomentam diferentes práticas ou estados de recepçáo e percepçáo. A visão e a audição continuam sendo, para o autor, os sentidos que mais conduzem e orientam o cotidiano no contexto da tecnologia informática. No entanto, acredita que o papel do som vem sendo valorizado.

Las tecnologías de las últimas tres décadas han incidido en la experiencia de todos, y no sólo en la de los músicos o los aficionados de este o aquel tipo de música. Hoy en día se ha ampliado el papel que la música - y la sonoridad en general - juega en la sociedad debido a la innovación tecnológica y los cambios en el consumo y la participación cultural. Entre otras cosas, percibimos que la música - y un sinnúmero de nuevos sonidos sintetizados - es cada vez más ubicua; casi no hay espacio donde no se oiga música. (YÚDICE, 2007, p. 18) 
iPods, música ambiente em elevadores e shoppings, cartóes de natal musicais, espera telefônica, rádio in door em supermercados são alguns exemplos mencionados por Yúdice como novos componentes de nossa experiência e paisagem acústica.

Além disso, no que se refere à música, surge um novo modelo de distribuição que ameaça o domínio da indústria fonográfica sobre os direitos autorais e a escolha do que será ouvido pelo público. Esse modelo vem sendo construído dia a dia por artistas e usuários da internet. A gravação e produção musical não dependem mais dos grandes estúdios fonográficos, fazendo surgir uma nova ética que promove a popularização e participação. Náo somente em termos de mercado se buscam novas maneiras de comercializaçáo dos produtos culturais, muito mais diretas entre artistas e seus públicos, mas também artisticamente, surgem estilos cada vez mais híbridos entre as culturas nacionais, como tangos japoneses e hip hop francês. "Esta hibridez muestra que la industria de la música no está determinando el $80 \%$ de lo que se escucha en el mundo. Muestra además que una verdadera world music se escapa de los cauces del marketing y de la nostalgia del folclore." (YÚDICE, 2007, p. 51).

A cultura do acesso, marcada pelo costume de escolher e baixar músicas gratuitamente pela internet, assim como decidir de quais redes e comunidades participar, faz com que as empresas busquem identificar o perfil de cada internauta para conseguir vender-lhe algo. É o começo do fim da comunicação de massa e o início de outro paradigma. Esse fenômeno é o que Anderson intitula mídia de cauda longa.

Enquanto a economia da era do broadcast visava difundir o mesmo produto para milhóes de pessoas ao mesmo tempo, o que demanda muito tempo e investimento para as redes de distribuição ponto a ponto, agora é possível oferecer uma infinidade de opçóes para cada consumidor. A cultura de massa continua existindo, mas atualmente os hits competem com inúmeros mercados de nicho. Os consumidores têm cada vez mais opções à sua disposição. "A era do tamanho único está chegando ao fim e em seu lugar está surgindo algo novo, o mercado de variedade." (ANDERSON, 2006, p. 5)

Alguns teóricos são bastante otimistas sobre esse contexto caracterizado pela autonomia, interação e participação dos usuários. É o caso de Kerckhove, para quem estamos passando do homo theoreticus ao homo participans.

[.. .] mientras la televisión siempre se ha percibido como un medio de difusión masiva, con un gran público, los ordenadores fueron personalizados como un medio de uso privado, solitario. Mientras la televisión proporcionaba un tipo de mentalidad colectiva para todo el mundo, pero sin entradas invididuales, los ordenadores eran mentes privadas sin entrada colectiva. La convergencia ofrece una nueva posibilidad sin precedentes: conectar a individuos y sus necesidades especiales en el seno de mentes colectivas. Esta nueva situación refuerza profundamente las capacidades personales y tiene repercusiones sociales, politicas y económicas. Acelerará los cambios y adaptaciones en la escena geopolitica, y también la sensibilidad privada de todo el mundo. Traerá consigo nuevas formas de conciencia y presionará en los sistemas educativos del planeta para que se hagan cargo de la nueva situación. (KERCKHOVE, 1999, p. 81). 
Essas mudanças representam uma transformação no caráter da comunicação, pois pela primeira vez na história um mesmo sistema integra as modalidades escrita, oral e audiovisual. Essa integração tem a característica de interatuar a partir de múltiplos pontos, em um determinado tempo, em uma rede global.

Lee Siegel não tem uma visão otimista sobre esse novo momento. Para ele, estamos entrando na época do Homo Interneticus, um ser cada vez mais ensimesmado e solitário e que quanto menos necessite a presença real de outra pessoa, mais dependerá de bens e serviços que lhe façam companhia. Este novo Homem vive em um mundo de inquietude, impaciência e ambição, cercado e às vezes constituído de histórias artificiais. $\mathrm{O}$ autor alerta que a ideia de cultura participativa e de "prosumidores", ou seja, usuários que também produzem e distribuem suas criações, contexto aparentemente mais democrático e descentralizador, pode ser uma falácia, que dá a ilusão de que as pessoas podem ter livre escolha e acesso a tudo na rede.

\section{[...] Internet ha puesto entre las cuerdas la "elección" y el "acceso". Nos ofrece opciones puramente por su propio interés. En Internet, la elección y el acceso nos conducen a más opciones, tantas, que compramos basándonos en el concepto de la alternativa disponible en lugar de hacer una elección especifica y concreta. (SIEGEL, 2008, p. 72).}

O contexto atual é fascinante, mas ao mesmo tempo desorientador, pois a abundância de informação não representa necessariamente conexôes em um mundo fragmentado. Numa mesma família, com o mesmo contexto socioeconômico e educativo, é possível encontrar sujeitos com gostos e comportamentos muito diferentes, porque sua socialização aconteceu em períodos distintos, regida pela leitura, pela televisão ou pela internet. Essas ideias enriquecem a observação de como as pessoas têm acesso à música na atualidade e quais os fatores envolvidos em suas escolhas de escuta.

\section{Gosto e estilo de vida}

Quando um ouvinte de rádio sintoniza em determinada emissora e programa, pressupóe-se nesta atitude um senso estético. Se depois de algum tempo, esse ouvinte deixa de gostar desse programa e passa a ouvir outra emissora, existe aí alguma motivação que nos interessa. Por que mudamos nossos gostos? Podemos modificar o gosto de outras pessoas? Para refletir sobre essas questóes, parte-se das reflexóes de Bourdieu sobre as intençóes envolvidas nos modos de produção de arte e a apropriação, percepção que se faz dela.

A intenção estética, para Bourdieu, é produto das convençôes sociais, está associada ao estilo de vida. A família e a escola têm importância fundamental na determinação do gosto. "Ao designar e ao consagrar certos objetos como dignos de serem admirados e degustados, algumas instâncias como a família e a escola são investidas do poder delegado de impor um arbitrário cultural" (BOURDIEU, 1987, p. 272). 
Diante do que afirma Bourdieu, é interessante citar que alguns ouvintes de rádio relatam uma certa repressão no ambiente doméstico ou em suas relaçôes pessoais por ouvirem determinados programas de "mau gosto" ou para se adequarem ao gosto do meio.

Na Caiobá toca música de baiano. (Daniela Anile, 17 anos, 2008)

[...] a Aline... ela gosta de umas músicas de velho. (Daniela Anile, 17 anos, 2008)

Meus filhos dizem: "ai, mãe, você é brega". (Aparecida Oliveira, 59 anos, 2008)

Eu gostava de pagode por influência dos amigos... fui obrigada a gostar. (Carolina Robassa, 16 anos, 2008)

Esses são alguns exemplos de como se dá a inculcação do gosto.

[...] na medida em que produz uma cultura (no sentido de competência) que não passa da interiorização do arbitrário cultural, a educação familiar ou escolar tem por efeito mascarar de modo cada vez mais acabado, através da inculcação do arbitrário, o arbitrário da inculcação, ou seja, o arbitrário das significaçôes inculcadas e das condições de sua inculcação. (BOURDIEU, 1987, p. 272).

O gosto é, portanto, um signo de distinção social. Cada campo de produção tem suas regras socialmente determinadas, tradiçóes herdadas.

Para Bourdieu, cada época organiza o conjunto de representaçóes seguindo um sistema de classificaçáo dominante. As diferenças e semelhanças entre diferentes tipos de representação já estão dadas por esse sistema. É como se toda obra de arte fosse produzida duas vezes, sendo a primeira pelo produtor e a segunda pelo grupo ao qual pertence o consumidor. A compreensão dos mecanismos de percepção é complementar à compreensão da própria produção artística. Os espectadores menos cultivados tendem a não perceber, compreender traços esteticamente pertinentes, e tendem a buscar uma percepção mais cotidiana, prática.

Qualquer mudança nos processos e produções artísticos acontece antes e prepara o terreno, condicionando uma transformação nas formas de percepção. Esse é um processo longo e difícil. O habitus cultivado se caracteriza por uma inércia que faz com que, "nos períodos de ruptura, as obras produzidas segundo um novo modo de produção estejam fadadas a serem percebidas, durante certo tempo, através dos instrumentos antigos de percepção" (BOURDIEU, 1987, p. 293).

\section{A mediação do rádio na apropriação musical}

Neste texto apresenta-se um recorte de uma pesquisa sobre a constituição do habitus do ouvinte de rádio no cotidiano familiar. Embora a investigação tenha tratado numa abordagem mais ampla sobre os hábitos dos ouvintes de rádio, suas falas e práticas de apropriação radiofônica, busca-se aqui oferecer 
uma visão específica sobre como o gosto musical dos jovens ouvintes vai sendo construído num contexto de múltiplas mediaçóes. $\mathrm{Na}$ etapa exploratória, a pesquisa envolveu 110 estudantes de Comunicação Social da PUC-PR que observaram os hábitos de suas famílias. Deste grupo inicial, 10 residências foram visitadas pela autora para, com base na metodologia de história de família, analisar o contexto da apropriação radiofônica em três geraçôes de ouvintes, sendo a primeira geração a dos avós dos estudantes, a segunda a dos pais, e a terceira a dos próprios jovens.

Os relatos demonstram que múltiplas mediaçôes ocorrem no processo da escuta musical. Para analisar essas mediaçóes, tomamos por base o modelo de Guilhermo Orozco (2006), inicialmente utilizado para os estudos de recepção de televisão, adaptando-o aqui à investigação sobre a apropriação radiofônica. A primeira das mediaçóes a serem observadas é a tecnológica. Neste sentido, é importante compreender como o veículo rádio se insere no cotidiano diante de outras tecnologias como a televisão, os equipamentos MP3, celulares e internet. A segunda mediação é a cognoscitiva, que se refere aos mapas mentais constituídos ao longo da vida de cada indivíduo a partir de sua interação social, às representaçóes construídas ao longo de sua trajetória e a partir de suas experiências. Entram aqui suas emoçóes, aspectos nostálgicos e o próprio sentido do escutar para cada sujeito.

A terceira mediaçáo é a situacional, considerando o cenário em que se dá a audição da música no cotidiano, o contexto momentâneo. Nesse aspecto, é considerada a inserção do rádio no espaço e no tempo do cotidiano das pessoas observadas, o uso que se faz dele, os "porquês" da escuta. A quarta mediação é a institucional, que diz respeito às diversas instituiçóes às quais o receptor se relaciona, à forma como a igreja, a escola e o Estado aparecem em suas escolhas e comportamentos como ouvinte ou não-ouvinte de rádio. A mediação referencial envolve a geração, o gênero e a etnia, que foram observados de maneira articulada na pesquisa.

Para melhor compreender o habitus geracional dos jovens ouvintes, convém aqui sintetizar esse movimento a partir das geraçôes anteriores. Nas famílias investigadas, a geração dos avós, que chamaremos de primeira geração, é a mais conectada ao rádio, juntamente com o uso da TV aberta. Essa geração acompanhou o período de ouro do rádio no Brasil e para ela este meio continua sendo importante em seu cotidiano, mesmo depois do surgimento da televisão e da Internet. Há em geral um caráter nostálgico em relação ao passado. $\mathrm{O}$ rádio está relacionado a sua origem, identidade e estilo de vida. Também está associado à ideia de modernidade, pois esse grupo viveu nas cidades em crescimento, com muitas transformaçóes no estilo de vida. $\mathrm{O}$ rádio foi (ou ainda é) o principal meio de entretenimento, sociabilidade e informação. A escuta radiofônica é organizadora do tempo cotidiano em função das atividades rotineiras, ou mesmo da própria programação radiofônica. A experiência de escutar rádio para esse grupo foi diferenciada em alguns aspectos, pois era comum que existisse somente um equipamento em cada casa e a escuta fosse coletiva, ou seja, em família. O rádio ocupava o tempo livre, quando as pessoas se sentavam na 
sala para escutá-lo. Seu som operava como som principal. Nessa geração, se pode notar menores mudanças de comportamentos em relação ao rádio a cada etapa da vida. Em geral, procuram seguir escutando os mesmos programas. Há um aspecto ritual em seu uso, sempre ao mesmo horário, mesmas vozes, nas mesmas circunstâncias. A audição das estaçôes AM é importante nesse grupo.

Todos que tinham o hábito cotidiano de escuta o mantém na atualidade, ainda que a maioria divida seu tempo com a televisão. O rádio fica ligado pela manhã, ou ainda de madrugada, enquanto as pessoas se despertam, tomam café da manhã e fazem as tarefas domésticas. À tarde, entra a televisão em cena permanecendo ligada até a hora de se deitar. Alguns voltam a ligar o rádio nesse momento. Os mais idosos costumam ouvir rádio como companhia e com a função de recordar o passado por várias horas ao dia.

Já os pais, a segunda geração, têm um forte vínculo com a televisão e seus hábitos em relação ao rádio dependem em grande parte de sua experiência familiar com esse meio, assim como com a apropriação de novas tecnologias. Portanto, são variáveis e assimétricos. O rádio está associado em todos os casos a recordações de infância com seus país e avós. Quando essas recordaçôes são prazenteiras, fica um elemento nostálgico que conserva o hábito de escuta cotidiana. Por outro lado, quando associados a relacionamentos difíceis ou mal resolvidos, as memórias costumam resultar em recusa pelo rádio. Em todos os casos, o rádio náo está mais conectado às ideias do novo e do moderno, ao contrário, costuma estar associado às ideias de passado e de tradição familiar, hora cultivada, hora rechaçada. Quando cultivada, apresenta naturalmente caráter nostálgico e de preservaçáo de ritos familiares.

$\mathrm{Na}$ medida de sua necessidade e oportunidade, essa geração também segue se apropriando das novas tecnologias de informação e de comunicaçáo ao longo de sua trajetória. Televisão a cabo e uso de DVD são generalizados. Somente em três das dez casas observadas náo havia o hábito de utilizar internet pelos integrantes dessa geraçáo. Para os que têm acesso cotidiano à rede, o uso mais frequente é para fins de trabalho e para baixar músicas para tocar em MP3. Às vezes o fazem de computadores pessoais de seus filhos e normalmente têm a ajuda deles para iniciar ou avançar em suas competências informáticas.

A audição ambiental é muito frequente nesse grupo, ou seja, o rádio fica ligado por todo o dia, no ambiente de trabalho, ou enquanto se executam outras tarefas domésticas. Em todos os casos, o rádio costuma ser ligado durante o dia, algumas vezes muito cedo e quase nunca à noite. $\mathrm{O}$ rádio opera como som de fundo, ou seja, em segundo plano. $\mathrm{O}$ número de equipamentos de rádio nas casas, variável de três até 13 , não equivale necessariamente ao tempo de escuta. Em algumas casas os aficcionados por rádio costumam deixá-lo ligado por várias horas ao dia, seja porque ficam sozinhos em casa, ou porque impóem a escuta aos demais. A escuta é imposta geralmente por parte dos homens. Com isso, temos o uso diário e prolongado do rádio em oito das dez casas investigadas. Nas demais famílias, a escuta de rádio se dá especialmente no carro, onde o motorista geralmente o pai, tem a autoridade sobre o dial. Nesses casos, a escuta tem o tempo de duração dos trajetos. 
$\mathrm{Na}$ segunda geração, se observam maiores mudanças de gosto e comportamento em relação ao rádio ao longo de suas trajetórias, sempre motivados por outra modalidade de mudança como de casa, emprego, morte ou nascimento de alguém da família, casamento, crise financeira, doenças, para mencionar alguns exemplos. Em seus usos atuais, o rádio é utilitário no trânsito, para aproveitar o tempo para se informar ou escutar música tranquila para relaxar.

\section{O perfil do ouvinte de terceira geração}

Para os jovens ouvintes, o consumo midiático é diversificado, tendo mais importância a Internet para os momentos de ócio, seguida pela televisão. Entretanto, o grupo também apresenta a maior diversidade nos modos de ouvir, em comparação com a geração de seus pais e avós, pois é adepto da escuta de arquivos em MP3 em tocadores digitais, rádio por celular e por internet, podcasts, webradios e sites musicais ou até mesmo estaçóes de rádio retransmitidas por TV a cabo. O uso mais frequente do rádio convencional se dá no carro, nos trajetos para a universidade e para o trabalho.

No caso do grupo investigado nessa pesquisa, tratam-se de estudantes de jornalismo e seus irmáos. Para todos os estudantes, o ingresso na universidade interferiu em seus hábitos, pois modificou seus gostos musicais por influência dos colegas. Todos demonstram esforço em adaptar-se a seus ambientes e serem aceitos pelos outros jovens. Costumam ouvir somente estaçóes FM. Para a maioria, o rádio é ligado por curtos períodos de tempo, seja no carro, no celular enquanto caminha ou pega ônibus, ou na internet. Apesar de estar ligado por períodos mais curtos de tempo, o rádio costuma ser o som principal, detendo a atenção auditiva em primeiro plano, ainda que a atenção visual seja utilizada simultaneamente para outra atividade, como dirigir ou navegar na internet.

O novo ouvinte não está obrigatoriamente arraigado ao território e às ondas hertzianas. É possível ouvir emissoras de qualquer parte do mundo pela internet estando em solo brasileiro e, estando fora do país, pode-se também acessar as emissoras locais e ouvir vozes "familiares". Ao ouvir música popular brasileira, poderá estar ouvindo uma música também de caráter transnacional, com múltiplas influências de ritmos e estilos mundiais.

Em meio a uma infinidade de referências musicais presentes na Internet e da diversidade de suportes existentes para a escuta musical, o rádio ainda opera como um selecionador de conteúdos, um balizador importante para o ouvinte internauta. Todos os ouvintes de terceira geração entrevistados e observados na pesquisa mencionaram ouvir rádio, especialmente no carro, e depois baixar as músicas da Internet para colocar em seus tocadores digitais. Em alguns casos, os jovens ensinam suas mães ou outras pessoas mais velhas da família a fazerem o mesmo, utilizando aplicativos de compartilhamento de arquivos como o E-Mule ou sites como o 4Shared.

O estudante Leandro Leite (19) conta que com 12 ou 13 anos seus amigos falavam muito da rádio $98 \mathrm{FM}$ e ele resolveu começar a ouvir para ter sobre o que conversar. Tocava muito Os Raimundos, que ele gosta até hoje. Por volta dos 14 anos, ele aprendeu a baixar músicas e trocar com os amigos. Tinha um 
gravador de $\mathrm{CD}$ no computador e juntava música contemporânea, anos 70 , MPB e rock. Ainda ouve a 98 FM, e também a Caiobá FM, duas emissoras que disputam o primeiro lugar de audiência, ou seja, se caracterizam como emissoras generalistas e de público massificado. Conta que leu sobre pagode e se interessou em ouvir. Leandro assiste a TV a cabo e usa a internet ao mesmo tempo, de três a quatro horas por dia em seu quarto.

Essa rotina demonstra que o rádio é apenas uma das diversas tecnologias de informação e comunicação que fazem parte da vida e do ânimo das famílias investigadas, integrando a apropriação do espaço doméstico e da organização do tempo no cotidiano. Morley ressalta a importância de náo analisar o uso dos meios de comunicação de maneira isolada.

Los mensajes que recibimos de los medios no nos encuentran aislados, porque todos llevamos con nosotros, en el momento de recibirlos, otros discursos y otro conjunto de representaciones con los que estamos en contacto en otras esferas de la vida. Los mensajes del momento confluyen con otros que hemos recibido antes, mensajes explícitos o implícitos de otras instituciones, de personas conocidas o de fuentes de información en las que confiamos. Inconscientemente, tamizamos y comparamos entre si los mensajes recibidos de una parte y de otra. De ahi que el modo en que respondamos a los mensajes que nos ofrecen los medios dependa precisamente del grado en que coincidan con otros mensajes (o se opongan a ellos), con otros puntos de vista que hayamos encontrado en otras esferas de nuestra vida. (MORLEY, 1996, p. 113).

Em uma outra família observada, Fernanda Robassa, de 10 anos, está na fase do computador. $\mathrm{Na}$ ocasiáo da pesquisa ouvia muito a Rádio Mix, uma emissora jovem que tocava músicas variadas e que foi indicada por uma amiga. Às vezes ligava na 98 para ouvir pagode. Costuma ouvir as músicas no rádio, descobre quem canta e depois baixa da internet. Escuta rádio antes de dormir e na escola ouve o MP3 no intervalo. No computador fica no MSN e Orkut, enquanto ouve música. Antes passava mais tempo diante da TV. Diz gostar da Rádio 98 porque toca músicas que a lembram da 5a série. As irmãs a chamavam de brega por ouvir essa emissora. Outro dia surpreendeu o pai repetindo o slogan da Lumen FM, uma emissora que toca pop contemporâneo segmentada nas classes A e B, rádio ouvida pelo pai e pela irmã mais velha que já está na universidade.

Os personagens entrevistados demonstraram mudanças de comportamento, especialmente durante a fase de transição para a vida adulta. A irmã de Fernanda, Carolina, de 16 anos, só ouve música baixada da internet. Não gosta de rádio, diz que puxou a mãe. Gostava de pagode, por influência dos amigos ("Fui obrigada a gostar"). Odeia as músicas que as irmãs escutam. Pede sempre para desligar o rádio. Ficava bastante na internet, agora fica menos, por causa do cursinho preparatório para o vestibular. O pai impóe a ela a escuta de notícias nos trajetos de carro, para que se prepare para o vestibular.

Em outra família observada, Fábio Pessoa, de 22 anos, prefere ouvir rádio pela internet. Ele se lembra de que ganhou um gravador quando tinha 8 anos. Ficava rodando e procurando músicas de que gostava. Ouvia sempre o que o pai ouvia, seguia o seu padrão. O pai entra na conversa e conta que 
embalava os filhos com o rádio ligado. Depois, com a internet, parou de gravar as fitas. Isso aconteceu em 1999. Lembra-se de ter lido em algum lugar que as rádios transmitiam pela internet e achou a BBC Radio 1. A partir de então, ouve todos os dias, ao vivo e on demand. Gosta de rock náo pesado e de contemporâneas pop.

A análise dos relatos e a observação das famílias demonstrou que todos esses fatores medeiam a escolha do que vai ser ouvido. As emissoras de rádio, seja na escuta musical direta pelas ondas hertzianas ou pela Internet, ainda são grifes de lançamento musical. Especialmente entre os jovens, fazem parte do processo de construção de identidades e do sentido de pertencimento. Mas tão importantes quanto as emissoras de rádio, outras grandes empresas de comunicação como as redes de televisão, os portais de conteúdos na internet oferecem o tempo todo suas sugestóes hegemônicas sobre o que deve ser ouvido.

É necessário registrar que este processo se mostra um tanto dinâmico e já há casos notáveis em que o rádio precisou repercutir sucessos lançados na Internet pelas redes sociais e não pelos grandes portais de conteúdo. Um caso mais recente registrado em Curitiba que merece ser citado foi o sucesso do clipe da Banda Mais Bonita da Cidade. Postado em redes sociais no dia 18 de maio de 2011, teve mais de quatro milhóes de acessos no You Tube até a conclusão deste artigo. Gravado em plano sequência, o clipe de aproximadamente 6 minutos tranformou a banda num fenômeno nacional, com solicitaçóes de entrevistas em redes de rádio e televisão, portais jornalísticos e convites de gravadoras. Os ingressos para o show que o grupo programava para o mês de junho se esgotaram em três horas (GAZETA DO POVO, 2011).

Na semana seguinte à "explosão", A Banda Mais Bonita da Cidade estava na Rádio Lúmen FM, dando entrevista e mostrando seu trabalho. No entanto, para o diretor do Grupo Lumen, Rulian Maftum, depois do boom na internet, a banda terá que adaptar seu repertório à linguagem radiofônica. "O que fez sucesso na internet foi o videoclipe, mas a banda precisa agora de produção musical para se tornar mais radiofônica”, explica. Segundo ele, para manter o sucesso o grupo terá que se adaptar ao mercado (do rádio e das gravadoras). "A música deles tem quase sete minutos, sem o apoio da imagem não dá pra ouvir", conclui.

Outro aspecto a ser analisado se refere a como as próprias emissoras de rádio têm se apropriado da internet. Observando os sites das emissoras de rádio direcionadas ao público jovem é possível perceber que o uso de ferramentas de interatividade e até mesmo das redes sociais ainda é bastante limitado. As emissoras utilizam promoçóes e enquetes para encaminhar os ouvintes aos seus sites e estimulá-los a participar e interagir com a programação. É o caso dos playlists, nos quais os ouvintes-internautas são convidados a votar nas músicas que vão compor a lista das mais pedidas. Essas interaçôes reproduzem modelos que já existiam antes, com a diferença que eram feitas por telefone. Os serviços de mensagem também foram incorporados pelas rádios substituindo as chamadas telefônicas, seja para pedir uma música ou votar para aprovar ou reprovar um lançamento. 
O ouvinte-internauta muitas vezes faz a ponte entre diferentes meios descobrindo uma canção no iPod do amigo, que por sua vez a ouviu a música na televisão, e sugerindo para a playlist de sua rádio preferida, que reforça o agendamento musical anteiormente pautado pela televisão, assim como outro jovem ao ouvir a música no rádio procura por ela na internet, baixa, se apropria de alguns bits, re-produz criando uma nova composição, distribuindo em sua rede social, que recebe referências sonoras aparentemente não identificáveis, mas que já fazem parte de um repertório sonoro que circula também nas mídias tradicionais.

É possível afirmar que as produçóes musicais ainda precisam articular diferentes mídias para serem encontradas pelos ouvintes na internet. Essa articulação, em geral, ainda é feita pelas grandes marcas como gravadoras, redes de televisão aberta e a cabo, estúdios de cinema, emissoras de rádio e mercado editorial com a publicação de revistas segmentadas e especializadas. Em meio à infinita oferta e variedade, o ouvinte recorre a filtros, mais dispersos e opacos, mas ainda hegemônicos, que ditam o gosto musical para a maioria.

\section{Referências bibliográficas}

ADORNO, T. O fetichismo na música e a regressão da audição. In: $O s$ pensadores. Tradução de: José Lino Grünnenwald et al. pp.165-191. São Paulo: Abril Cultural, 1980.

ANDERSON, C. A cauda longa. Do mercado de massa para o mercado de nicho. Rio de Janeiro: Elsevier, 2006.

BOURDIEU, P. A economia das trocas simbólicas. São Paulo: Perspectiva, 1987.

CEBRIÁN HERREROS, M. La radio en Internet. Buenos Aires: La Crujía, 2008.

GAZETA DO POVO. Um clipe e, de repente, o sucesso. Disponível em http://www.gazetadopovo.com.br/cadernog/conteudo.phtml?id=1130929. Acesso em 02 de junho de 2011.

KERCKHOVE, D. La piel de la cultura: investigando la nueva realidad electrónica. Barcelona: Gedisa, 1999.

MATALLANA, A. Locos por la radio: uma historia social de la radiofonía en la Argentina, 1923-1947. Buenos Aires: Prometeo Libros, 2006.

MORLEY, D. Televisión, audiências y estúdios culturales. Buenos Aires: Amorrortu, 1996.

OROZCO, G. G. Recepción y mediaciones: casos de investigación en América Latina. Colombia: Norma, 2006.

SIEGEL, L. El mundo através de una pantalla: ser humano en la era de la multitud digital. Barcelona: Tendências, 2008.

YÚDICE, G. Nuevas tecnologías, música y experiéncia. Barcelona: Gedisa, 2007. 